\title{
Proceedings of the 120th Meeting of the Society of British Neurological Surgeons held jointly with the Swiss Neurosurgical Society, Lausanne, Switzerland, 27-29 May 1992
}

GUEST LECTURERS: Surgery of AVMs-GM Yasargil (Zurich); Litigation in lumbar surgery—JS Garfield (Southampton); Clinical perspectives of recent advances in neuroprotection- $\mathbf{R}$ Bullock (Glasgow).

PREDICTION OF OUTCOME IN SUBARACHNOID HAEMORRHAGE

G Neil-Dwyer, C Gerber, D Lang, P Smith, D Lowe. Southampton

In three studies, known risk factors were used to predict outcome following a subarachnoid haemorrhage. In the first study 27 variables were examined to assess their relative predictive strength. Neurological grade and basal or ventricular blood on the CT scan emerged as strong predictors of outcome. A scoring system was developed based on the best neurological grade within 3 days of a haemorrhage and the presence of blood in certain sites on the CT scan. Patients were divided into low, medium and high risk groups. In this study over $80 \%$ of low risk patients experienced a full recovery at 3 months compared to less than $10 \%$ of high risk patients. In two subsequent studies separated by 5 years and performed in 2 different Units (Brook Hospital, London and Southampton), prospective application of the scores achieved similar results to the first study. Statistical analysis confirmed that the probability of a good outcome in the low risk category is significantly greater than any other possible outcome. By contrast in the high risk group the results point to death as the most likely outcome.

SUBARACHNOID HAEMORRHAGE AND INTRACRANIAL ANEURYSMS IN THE ELDERLY A REVIEW OF 180 CASES WITH LONG TERM FOLLOW UP

MG O'Sullivan, N Dorward, AJ Steers, JD Miller. Edinburgh

Subarachnoid haemorrhage in the elderly (over 60 years) has received little attention in the neurosurgical literature and opinions on the advisability of aneurysm surgery have been conflicting. ${ }^{12}$ The authors reported a retrospective study of 180 cases managed over a 9 year period. The patients were analysed with respect to angiography, WFNS grade, site of aneurysm, operation and outcome. There were 55 males and 125 females. 80 patients were 61-64 years, 59 were 65-69 years and 41 were 70 years or over.

A total of 45 patients did not have angiography. Of the 135 who did, 33 were angiogram negative, 84 had surgery for an aneurysm and 18 had an aneurysm disclosed but no operation. Survivors were followed up for a median of $\mathbf{4 8}$ months (range 12-120). Seven patients died of neurological disease and 15 died of other causes. Three patients had further "strokes". The management mortality was $23 \%$. Sixteen (9\%) patients were severely disabled, 13 (7\%) were moderately diśabled and 109 (61\%) had a good outcome. The surgical mortality was $2 \%$ with 11 (13\%) severe disabilities, $7(8 \%)$ moderate disabilities and $64(76 \%)$ good outcomes.

The authors concluded that elderly patients in good condition following subarachnoid haemorrhage should be managed by disclosure and clipping of the responsible aneurysm: the long term prognosis for surviving patients is favourable.

\section{Martindale BV, Garfield J. BMF 1978;1: 465-6. \\ 2 Amacher AL, Feguson GG, Drake CG, et al.} Neurosurgery 1977;1:242-4.

INITIAL EXPERIENCE WITH THE USE OF CYANOACRYLATE FOR THE EMBOLISATION OF LARGE CEREBRAL ARTERIOVENOUS MALFORMATIONS

JE Dervin, R Bullock, A Burke, S Sloss. Glasgow

Sixty four patients presented with an arteriovenous malformation (AVM) over the four year period 1988-91. Forty two of these were managed surgically and seven by stereotactic radiotherapy. Fifteen large AVMs (Spetzler Grade III-VI) were selected for cyanoacrylate embolisation. In this group, 42 embolisations were performed by the transfemoral route, using superselective catheterisation with flow-or guidewiredirected catheters. N-butyl cyanoacrylate was injected in large volumes in a continuous column, under general anaesthetic, to render the AVM suitable for surgery or radiotherapy. No major complications were seen. A transient increase in the severity of an existing hemiplegia occurred in one case. In another, a catheter tip was glued in; this was retrieved during surgical removal of the malformation, without sequelae. In two patients with ruptured AVMs, complete surgical excision was performed. Conventional surgical techniques may need modification after cyanoacrylate embolisation. In those with unruptured AVMs, $25 \%-95 \%$ reduction had been achieved. Improvement in symptoms such as seizures, hemiparesis, dysphasia and higher mental function was achieved with embolisation in many of these patients. No patient sustained a haemorrhage after cyanoacrylate embolisation. Initial experience suggested that cyanoacrylate is a safe and effective embolic material for brain AVMs prior to surgery. Careful follow up from multiple centres will be necessary to determin whether embolisation can provide definitive protection against haemorrhage.

MISLEADING IMAGING AND "SCARECTOMY" FOLLOWING LUMBAR DISC SURGERY PO Byrne, M Sharr. Brook Hospital, London

Nine patients (23-56 year of age) with typi- cal sciatica and prolapsed intervertebral discs $(5 \mathrm{~L} 4 / 5 ; 4 \mathrm{~L} 5 / \mathrm{S} 1$ confirmed on radiography \pm CT scan) initially recovered following disc removal through a fenestration approach with operative confirmation of the $x$ ray findings (bony canal stenosis (1) sequestered disc (2), damaged dural root sleeve (1)). However, symptoms recurred 4 months to 9 years later. CT radiculography (6) or MRI (3) demonstrated recurrent disc protrusion in all patients ( + root canal stenosis (3); scarring (2)), but no recurren disc was found at re-exploration in any patient: only dense scarring (+ root canal stenosis (2)). Scar tissue was excised with good symptomatic relief in 8 patients (follow up: 13-24 months). The authors concluded that radiology including MRI is difficult to interpret following surgery and excision of scar tissue may be surprisingly useful.

PROGNOSTIC FACTORS INFLUENCING THE NEED FOR PERMANENT CSF DIVERSION IN PRIMITIVE NEUROECTODERMAL TUMOURS (PNET) OF THE POSTERIOR FOSSA S Chatterjee, P May. Liverpool

Primitive neuroectodermal tumours (PNET) are the most common malignant CNS tumours of childhood. Those in the posterior fossa often obstruct CSF pathways causing hydrocephalus. While the majority will have their hydrocephalus relieved by resection of the tumour, there exists a subgroup where a permanent shunt becomes necessary at some time in the postoperative period. Which factors influence the need for permanent shunt procedures?

The medical records were analysed for 70 paediatric patients with PNET who presented to the unit between 1976-91. Patients who had a shunt inserted before resection of tumour were not included in the study. A total of 22 patients (31\%) required a permanent shunt, whereas 48 patients $(69 \%)$ did not require a shunt procedure. The two groups were compared with respect to various prognostic factors. Age was found to be the most significant factor with mean age in shunted group being 5.1 years compared with 9.9 years in the non-shunted group. Other factors were compared using non-parametric methods for unpaired data: presence of signs of raised ICP at the time of presentation $(p=$ 0.016 ), duration of symptoms at the time of first presentation $(p=0.021)$, degree of hydrocephalus $(p=0.014)$, and the Chang stage $(p=0.033)$. Presence of CSF leak, meningitis, metastatic disease, dural closure, extent of resection, and type of adjuvant therapy did not differ significantly between the two groups.

In conclusion, age was found to be the most important factor with $50 \%$ of patients 
below the age of five years requiring a shunt.

SPINAL DURAL ARTERIOVENOUS

MALFORMATIONS-AN UNDER-DIAGNOSED CAUSE OF LEG WEAKNESS IN THE ELDERLY? RS Maurice-Williams. Royal Free Hospital, London

Nine patients (age 47-76 years; $7 \mathrm{M} / 2 \mathrm{~F}$ ) had presented over a 7 year period to the author with slowly progressive paraparesis for some months culminating in a phase of rapid deterioration over 24 hours. A spinal dural AVM was demonstrated by myelography (8 patients) and spinal angiography ( 9 patients). Following division of the bridging vein running from the arteriovenous fistula to the coronal venous plexus of the cord, all nine patients showed substantial recovery without complications. There were no relapses at follow up of up to $2 \frac{1}{2}$ years. These malformations may well be acquired rather than congenital in nature, and it is possible that they are a relatively common cause of progressive leg weakness in the elderly. The gradual onset of symptoms, the non-specific findings on neurological examination and the fact that many non-neurologists are probably unaware of this pathological entity, means that the condition is easily overlooked. Further hindrances to the diagnosis are the replacement of myelography by more modern imaging techniques and the fact that when myelography is carried out, the characteristic serpiginous filling defects in the contrast column can easily be overlooked by the non specialist radiologist.

ACUTE SUBDURAL HAEMATOMA-

PREDICTORS OF OUTCOME IN 214 PATIENTS ATH Casey, RJ Cook, MR Fearnside, BA Bell. Atkinson Morley Hospital, London, and Westmead Hospital, Sydney, Australia

The diagnosis of an acute subdural haematoma correlates with a severe head injury and a high mortality rate in most series. The widespread adoption of the Glasgow coma scale (GCS) and the Glasgow outcome scale (GOS) has facilitated collation of data from different units. In this study, 103 patients from Westmead Hospital, Sydney, Australia, and 111 patients from Atkinson Morley's Hospital, London, with a diagnosis of acute subdural haematoma were evaluated. All patients who were not in coma (GCS > 8) achieved a functional outcome (GOS 1 or 2) six months following their injury. Patients who were in coma (GCS $\leqslant 8$ ) had a $54 \%$ mortality with only $30 \%$ achieving a functional outcome (GOS 1 or 2 ).

Clinical data and CT scans were analysed and age over 60 years $(p<0.0004)$, hypoxia $(p<0.0001)$, hypotension $(p<$ $0.036)$, pupillary response ( $p<0.0014)$, response to treatment of raised intracranial pressure $(p<0.05)$, and the degree of midline shift $(p<0.002)$ on the CT scan were significant predictive factors of outcome. It was notable that the time to surgical intervention was not found to be important in contrast to Seelig's study. ${ }^{2}$ Furthermore, the mechanism of injury, a lucid interval, subdural haematoma volume, effacement of basal cisterns, intraventricular blood, subarachnoid haemorrhage, and extracranial injuries, did not predict outcome.

Priorities of pre-surgical management are the correction of hypoxia and hypotension. The wisdom of surgical intervention in the comatose elderly patient ( $>70$ years, GCS $\leqslant 8$ ) is doubtful with no functional outcome in this group. The surprising finding that neither subdural haematoma volume nor operative timing appeared to affect outcome raises the question as to whether the haematoma is an epiphenomenon with the degree of underlying brain damage being the more significant factor.

1 Gennarelli TA, Spielman GM, Langfitt TW, et al. I Neurosurgery 1982;56:26-32.

2 Seelig JM, Becker DP, Miller JD, et al. New Eng $\mathcal{F}$ Med 1981;304:1511-8.

PRELIMINARY REPORT OF A NEW SYSTEM FOR CAPTURING AND TRANSMITTING COMPUTED TOMOGRAPHIC IMAGES

WP Gray, TF Buckley. Cork, Ireland

The value of interhospital transmission systems for CT images is well recognised. ${ }^{1}$ They improve the clinical management of emergency neurosurgical referrals and avoid unnecessary interhospital transfers. However, these systems are expensive since they require a direct hardware connection to the CT scanner. The authors described the development of a new system which obviated the need for any connection to the CT scanner. This was achieved using a handheld optical scanning device which read the image from the printed hard copy of the scan as it was drawn across it. The device transferred the image to a personal computer which automatically sent it to the receiving computer over a normal telephone line. Typical transfer times were 40 to $90 \mathrm{sec}$ onds at 9600 baud for a 256 grey scale image. This system had been tested successfully over long distances. It reliably delivered high quality images at low cost.

$$
1 \text { Lee T. Lancet 1990;336:101-3. }
$$

\section{RECOVERY OF VISION FOLLOWING}

TRANSPHENOIDAL AND TRANSCRANIAL

SURGERY FOR PITUITARY ADENOMA AND CRANIOPHARYNGIOMA

M Powell, C Grint, P Kelland, J Oben. National Hospital, London

The results in 50 patients were reported of surgical decompression performed between 1985-90 (43 transphenoidal; 9 primary craniotomies; 3 secondary craniotomies) for visual failure caused by pituitary adenoma (44) or craniopharyngioma (6). One patient died 19 days postoperatively from an unrelated carcinoma. Neuro-ophthalmic assessment was performed independently preand post-operation and then at regular follow up, using Goldman Fields. Of the 48 with field defects, 14 regained full fields, 25 improved and 7 did not change. In 46 with diminished acuity, 17 regained $6 / 6$ vision bilaterally, 18 improved, 4 did not change and 7 deteriorated. Of 32 patients with optic atrophy, 2 were apparently cured, 2 improved and 25 remained unchanged. Normal pituitary function was preserved in 17 patients, 8 required thyroxine and hydrocortisone and 7 required additional sex hormone replacement. Four developed diabetes insipidus. Current hormone status was unavailable in 14 patients.
TRANSCALLOSAL OR TRANSCORTICAL EXCISION FOR COLLOID CYSTS OF THE THIRD VENTRICLE?

SR Stapleton, AJ Moore, HT Marsh, BA Bell, D Uttley. Atkinson Morley's Hospital, London

In 1921 Dandy performed the first successful operation to excise a colloid cyst of the third ventricle using a transcortical approach. $^{1}$ In 1949 Greenwood described two cases using a transcallosal approach. ${ }^{2}$ Although stereotactic techniques have been used recently they require further evaluation. Each open approach has its advantages and disadvantages related to access, retraction and complications, particularly postoperative seizures, but they have rarely been compared directly.

Since the introduction of the CT scanner in 1973, 39 patients with colloid cysts of the third ventricle had been seen. Twenty had been excised transcortically and 14 transcallosally. The remainder had had a variety of shunt or stereotactic procedures. Nine patients required emergency ventricular decompression. Postoperative epilepsy occurred in $3(15 \%)$ transcortical and in 2 (14\%) transcallosal cases, the latter being complicated by frontal retraction contusion or venous infarction. Memory disturbance occurred in 7 (35\%) transcortical and in 4 (36\%) transcallosal cases.

These figures demonstrate the generally good outcome following surgery for colloid cysts using either approach. However, unless the transcallosal approach can be performed without undue retraction on the frontal lobe or divison of draining veins, the potential benefits of this approach in reducing the risk of postoperative epilepsy will be lost. Both approaches may cause memory disturbance, personality changes or a hypothalamic disturbance, all of which are usually transient.

$$
\begin{aligned}
& 1 \text { Dandy WE. Benign tumours of the third ventricle } \\
& \text { of the brain: diagnosis and treatment. } \\
& \text { Springfield, Illinois: Charles C Thomas, } \\
& 1933 \text {. } \\
& 2 \text { Greenwood J. I Neurosurg 1949;6:153-9. }
\end{aligned}
$$

DIAGNOSIS OF CSF LEAKAGE-PARAGON IMMUNOFIXATION MSM Eljamel. Dublin

It is often difficult to be certain that the leaking fluid is CSF, particularly when the fluid may be mixed with blood, nasal secretions or wound discharge. There are no pathognomonic clinical signs of CSF fistulae and chemical analysis of the fluid for glucose and protein carries a 45 to $75 \%$ false positive rate. $B_{2}$-Transferrin is a byproduct of the neuroaminidase activity of the brain and in practice has been found only in the CSF. It contains fewer sialic acid radicals and therefore migrates slower on electrophoresis than its counterpart $B_{1}-$ Transferrin. The aim of this study was to determine the reliability of $\mathbf{B}_{2}$-Transferrin identification, using Paragon \& gel immunofixation techniques to differentiate CSF from its contaminants during CSF leakage. A total of 114 samples of CSF and potential CSF contaminants during CSF leakage (blood, wound discharge or nasal secretions) were examined blindly by the usual Glucose-Oxidase Stick Test and the Paragon(B) Gel immunofixation technique to identify $\mathrm{B}_{2}$-Transferrin. $98 \cdot 3 \%$ (57/58) of the samples containing CSF showed the $B_{2}$-Transferrin band as well as 
the $B_{1}$-Transferrin band. None of the other samples were positive for the $\mathrm{B}_{2}$-Transferrin band. All blood and wound discharge samples and two nasal secretion specimens showed a single ( $B_{2}$-Transferrin) band. The specificity of the $\mathrm{B}_{2}$-Transferrin band was $99 \%$. There were no false positive results in this study. One sample containing CSF obtained through an external ventricular drainage system was negative for the $B_{2}$ Transferrin band. Subsequent measurement of the protein content of this sample was unusually low (10 $\mathrm{mg} \%)$. The lowest concentration of CSF detectable with this method was $10 \%$ for any sample. If the CSF contaminant to pure CSF ratio was more than 10 to 1 the $B_{2}$-Transferrin band was not detectable.

The author suggests that accurate and specific diagnosis of CSF leakage is now possible, by using the Paragon $\AA$ immunofixation technique to detect the $\mathbf{B}_{2}$ Transferrin band.

A MODIFIED FRONTAL APPROACH FOR ANTERIOR CIRCLE OF WILLIS ANEURYSMS PD Lee, G Neil-Dwyer. Southampton

The pterional approach to anterior circulation aneurysms had been modified in over 50 patients so that the surgeon (and assistant) stood beside the chest similar to the Hardy transphenoidal position. The surgeon stood on the ipsilateral side for anterior cerebral and on the contralateral side for middle cerebral aneurysms with only a slight modification of the standard head position. The authors considered the major advantage of the approach was that the view of the surgeon was along the plane of the vessels in keeping with standard anatomical and radiological illustration. This foreshortened the proximal artery, gave earlier visualisation of branches, proximal control and less brain retraction. Brain retraction had been reduced further by incorporating a superior orbitotomy to increase the intracerebral angle of view. Additional advantages had been ease of access for the scrub nurse to both hands of the surgeon. The assistant found the position more comfortable and access easier. Instruments were not introduced over the brain thereby protecting the cortex and the skull base had provided a rigid support for the clip-applying hand.

GLUTAMATE NEUROTOXICITY IN THE NORMAL RAT BRAIN: FIRST RESULTS OF A NEW IN VIVO MODEL

H Landolt, H Fujisawa, DI Graham, WL Maxwell, J McCulloch, R Bullock. Basel, Switzerland and Glasgow

There is considerable evidence linking raised cerebral extracellular concentration of glutamate to cerebral infarction in the rat subdural haematoma preparation. The authors reported the correspondence between the volume of the sharply defined lesions (measured volumetrically in perfusion-fixed and haematoxylin-eosin stained frozen sections) produced by different concentrations $(0.01,0.1,0.5,1$ molar) of monosodium glutamate applied for $90 \mathrm{~min}$ utes by microdialysis into the frontoparietal cortex of Sprague Dawley rats and the volume of diffusion of ${ }^{14} \mathrm{C}$-glutamate. The 2-deoxy- ${ }^{14} \mathrm{C}$-glucose autoradiograms dem- onstrated a similar area of reduced uptake with a peripheral zone of hypermetabolism.

MIDDLE CEREBRAL ARTERY OCCLUSION WITHOUT CRANIECTOMY IN RATS. WHICH METHOD WORKS?

RJC Laing, J Jakubowski, RW Laing. Sheffield

For many years investigators have sought a minimally invasive rodent model of focal ischaemia. The technique should be simple, reproducible and have low mortality. The effectiveness of middle cerebral artery (MCA) occlusion in producing acute focal ischaemia in the anaesthetised rat had been assessed using Koizuma's ${ }^{1}$ and Longa's ${ }^{2}$ method where the occlusion is achieved by passing a nylon thread up the internal carotid artery. The changes in cerebral blood flow (CBF) were measured over a period of six hours using the $\mathrm{H}_{2}$ clearance method and the brains were examined histologically.

Using Koizumi's Technique profound reduction in CBF was achieved in 28 out of 30 animals (93\%), with mean CBF in the MCA territory of $11 \mathrm{ml} / 100 \mathrm{gm} / \mathrm{min}(95 \%)$ confidence intervals $(10-12)$. Using Longa's method reduction in CBF was achieved in only 29 out of 52 animals (56\%) with a mean CBF of $33(28-34)$ $\mathrm{ml} / 100 \mathrm{gm} / \mathrm{min}$. In only 18 animals (35\%) was there a reduction in CBF below 25 $\mathrm{ml} / 100 \mathrm{gm} / \mathrm{min}$. Using Koizumi's method the depth of ischaemia is more profound, occlusion is achieved in a much higher proportion of cases and the incidence of trauma to the vessels is much less frequent than in Longa's method.

1 Koizumi J, et al. Fpn $\mathcal{Y}$ Stroke 1986;8:1-8.
2 Longa EL, et al. Stroke 1989;20:84-91.

MIDDLE CEREBRAL ARTERY FLOW VELOCITIES DURING NEURO-ANAESTHESIA: COMPARISON BETWEEN CONTROL AND ANEURYSM PATIENTS

JC Sutcliffe, OCE Sparrow, L Chadwick, M Dojcinovska. Royal London Hospital and Romford

Transcranial Doppler was used to study changes in middle cerebral artery velocity during different stages of neuroanaesthesia in fifteen control patients and ten patients undergoing craniotomy for clipping of a ruptured intracranial aneurysm. In the control group peak flow velocity, measured at each stage of the anaesthetic, showed a predictable and consistent pattern with maximal velocities at the time of intubation and extubation; no such pattern existed for the aneurysm group. In the control group, there was a linear relationship between heart rate and peak flow velocity which was not seen in the aneurysm group. Pulsatility index varied in each control patient during anaesthesia and surgery, tending to be maximal after induction and before reversal of anaesthesia. This trend was not seen in the aneurysm group, in whom the absolute values were higher and the variation much greater. The authors considered that the marked variability in peak flow velocities during anaesthesia, the deviation from the pattern seen in control patients and failure of the pulsatility index to rise after induction indicated loss of autoregulation in the SAH patient. Furthermore, heart rate was an important determinant of middle cerebral artery velocity.

THE EFFECT OF CHANGES IN CEREBRAL HAEMODYNAMIC FACTORS ON INTRACRANIAI BLOOD FLOW VELOCITY AND JUGULAR VENOUS BULB OXYGEN SATURATION AFTER SEVERE HEAD INJURY

KH Chan, JD Miller, NM Dearden, PJD Andrews, S Midgley. Edinburgh

The relationship between middle cerebral artery (MCA) blood flow velocity and jugular bulb oxygen saturation $\left(\mathrm{SJO}_{2}\right)$ and changes in blood pressure (BP), in 41 severely head-injured patients. They had continuous monitoring of BP, ICP, arterial oxygen saturation, end-tidal carbon dioxide concentration, MCA flow velocity by transcranial Doppler (TCD) and 22 had $\mathrm{SJO}_{2}$ recordings. TCD time-averaged mean velocity and pulsatility index (PI) were measured. Data obtained after ICP therapy were excluded.

CPP was reduced both by raised ICP and by reduced BP at different times. Both forms of reduction in CPP resulted in greater decrease in MCA diastolic flow velocity than other velocity parameters. Linear correlations were noted between time-averaged mean velocity and ICP $(r=$ $-0.32, p<0.001)$, BP $(r=0.27, p<$ $0.001)$ and $\operatorname{CPP}(r=0.48, p<0.001)$. Better correlations existed between PI and ICP $(r=0.44, p<0.001)$, BP $(r=-0.45$, $p<0.001)$, and CPP ( $r=-0.73, p<$ 0.001 ). Linear correlations were also observed between $\mathrm{SJO}_{2}$ and ICP $(\mathbf{r}=$ $-0.38, p<0.001)$, and CPP $(r=0.52, p<$ $0.001)$, but not with BP $(r=0.12, p=N S)$ Both $\mathrm{PI}$ and $\mathrm{SJO}_{2}$ correlated better with CPP than ICP or BP. An alternative analysis revealed that as CPP decreased below a critical level of $70 \mathrm{mmHg}$, a progressive increase in PI was noted $(r=-0.94, / p<$ $0 \cdot 0001)$, accompanied by a fall in $\mathrm{SJO}_{2}(\mathrm{r}=$ $0.78, \mathrm{p}<0.0001)$. The relationship between PI and CPP held true in patients with both focal and diffuse pathology and was the same whether changes in CPP resulted from alterations in ICP or BP. Above $70 \mathrm{mmHg}$, there was no correlation between either PI or $\mathrm{SJO}_{2}$ against CPP.

TCD can identify states of reduced CPP. Decreases in mean flow velocity and $\mathrm{SJO}_{2}$ with falling CPP suggest progressive failure of cerebral blood flow to meet metabolic demands; increases in PI with reducing CPP indicate the exhaustion of the process of autoregulation. TCD and $\mathrm{SJO}_{2}$ may be used to define the optimal CPP level (70 $\mathrm{mmHg}$ ) for management of severely braininjured patients. This level is higher than previously recognised.

DOES STEREOTACTIC BIOPSY ACCURATELY PREDICT PROGNOSIS IN CEREBRAL GLIOMA? T Revescz, F Scaravilli, HAC Cockburn DGT Thomas. National Hospital, London

Stereotactic brain tumour biopsy obtains small samples and a theoretical criticism of the method is that these may not be representative of the tumour as a whole, leading to less accurate histological grading and prognosis than that provided by other methods. A series of 160 cases of supratentorial gliomas in adults were graded histologically by the Kernohan and by the 
Daumas-Duport methods and clinical follow up data obtained. When the Kernohan grading system was applied, low grade gliomas (grades 1 and $2, \mathrm{n}=53$ ) had a better survival probability $(p<0.0001)$ than high grade tumours (Grade 3, n = 57 and Grade 4, $n=50$ ). However, using the Kernohan grading system there was no significant difference between Grade 3 and Grade 4 tumours $(p<0 \cdot 1)$. By contrast, when the Daumas-Duport grading system was applied, highly significant differences in probabilities of survival were found not only between Grade $2(n=38)$ and Grade 3 ( $n$ $=41),(p<0.0001)$ but also between Grade $3(n=41)$ and Grade $4(n=80)(p<$ 0.0001 ).

These findings indicate that histological grading of stereotactic biopsy material is satisfactory for prognosis as between low grade and high grade cerebral gliomas both by the Kernohan and Daumas-Duport systems with the latter method providing further prognostic distinction between Grade 3 and Grade 4 tumours.

Titles of papers presented by members of the Swiss Neurosurgical Society

PERIOPERATIVE MANAGEMENT IN EARLY ANEURYSM SURGERY: EXPERIENCE IN 90 CONSECUTIVE CASES

F Porchet, $\mathbf{N}$ de Tribolet, $\mathbf{R}$ Chiolero. Lausanne, Switzerland

HIGH ALTITUDE INTRACRANIAL HAEMORRHAGE: REPORT OF TWO CASES S Stephanov, J de Preux. Sion

GROWING GIANT INTRACRANIAL ANEURYSMS: PRESENTATION OF THREE CASES

A Barth, $\mathbf{O}$ Vernet, $\mathbf{N}$ de Tribolet. Lausanne, Switzerland

LYTIC SPONDYLOLISTHESIS: LONG TERM RESULTS FOLLOWING RADICULAR DECOMPRESSION AND POSTERIOR LUMBAR INTERBODY FUSION (PLIF) IN 40 CONSECUTIVE CASES

G Costabile, Ch Probst. Aarau

PERIPHERAL ENTRAPMENT NEUROPATHIES OF THE PRIMARY DORSAL BRANCHES-THE MOST COMMON CAUSE FOR ACUTE AND CHRONIC BACK-PAIN

HsR Richter. Basel, Switzerland
PRETREATMENT WITH CHYMOPAPAN MIGHT IMPROVE RESULTS IN PERCUTANEOUS LUMBAR DISCECTOMY

A Merlo, D Stula. Basel, Switzerland

DECOMPRESSION AND STABILISATION BY TRANSLAMINAR FACET SCREW FIXATION IN DEGENERATIVE LUMBAR SPINE DISORDERS A Benini, F Magerl. St Gallen, Switzerland

LONG TERM RESULTS AFTER VENTRICULOATRIAL SHUNTING IN CHILDREN O Vernet, $\mathbf{R}$ Campiche, $\mathbf{N}$ de Tribolet. Lausanne, Switzerland

TETHERED SPINAL CORD: MICROSURGICAL TREATMENT WITH ELECTROPHYSIOLOGICAL MONITORING

K Kothbauer, UD Schmid, RW Seiler. Bern, Switzerland

SPINAL CORD LESION AFTER GRAFTS OF EMBRYONIC MOTORNEURONES INDUCES MOTORNEURONE DEATH IN ADULT SPINAI CORD OF MICE: NEURODEGENERATION CAN BE SPARED BY METHYLPREDNISOLONE AND AN NMDA ANTAGONIST IN MOUSE SPINAL CORD

B Demierre, L Mattengerger, A Kato. Geneva, Switzerland

\section{SOLITARY CERVICAL INTRAMEDULLARY} NEURINOMA

RS Binggeli, U Ebeling, RW Seiler. Bern, Switzerland

SOLITARY OSTEOCHONDROMA PRESENTING AS A NECK MASS WITH SPINAL CORD COMPRESSION SYNDROME

M Morard, J de Preux. Sion

SPINAL MENINGIOMAS: FACTORS AFFECTING RECURRENCE

B Ferrero, G Pizzolato, J Berney. Geneva, Switzerland

PRIMARY MELANIC TUMOURS OF THE CENTRAL NERVOUS SYSTEM: MALIGNANT OR BENIGN?

A Reverdin, A Barth, G Pizzolato, J Berney. Geneva, Switzerland
THE EVALUATION OF MILD HEAD INJURY: THE ROLE OF PLAIN SKULL X RAYS

H-G Imhof, $\mathrm{K}$ Käch, T Kossmann, C Marganti-Kossmann, R Stocker. Zurich, Switzerland

HIGHER THAN RECOMMENDED DOSAGE OF RIFAMPICIN IN CEREBRAL INFECTIONS? Th Mindermann, $H$ Landolt, W Zimmerli, O Gratzl. Basel, Switzerland

DIGITAL MICROSCOPY FOR STEREOTACTIC MICROSURGERY

HF Reinhardt, GA Horstmann. Basel, Switzerland

ROBOTICS IN NEUROSURGERY

H Fankhauser, J Favre, D Glauser. Lausanne, Switzerland

CT-GUIDED STEREOTACTIC ASPIRATION AND TREATMENT OF BRAIN IN ABSCESSES MG Hasdemir, U Ebeling, HJ Reulen, $P$ Huber. Bern, Switzerland

CHRONIC THALAMIC ELECTRICAI STIMULATION VERSUS THALMOTOMY FOR THE TREATMENT OF TREMOR: INDICATIONS, ADVANTAGES AND LIMITS

J Siegfried. Zurich, Switzerland

INTRAOPERATIVE SPEECH MAPPING DURING RESECTION OF TUMOURS IN THE POSTERIOR DOMNNANT TEMPORAL LOBE

U Ebeling, $\mathbf{W}$ Eisner, $\mathrm{K}$ Gutbrod, I Imberger, UD Schmid, HJ Reulen. Bern. Munich

MICROSURGICAL DREZ-TOMY FOR PAIN AND SPASTICITY

B Demierre, Y Blanc, A Carota, J Berney. Geneva, Switzerland

NERVE GROWTH FACTOR ENHANCES THE GROWTH OF AXONS AND DENDRTES OF CHOLINERGIC NEURONS IN ORGANOTYPIC CULTURES OF NEONATAL RAT STRIATUM L Studer, C Spenger, $R$ Seiler. Bern, Switzerland 